\title{
New Synthetic Drugs in Addictovigilance
}

\author{
François Chavant ${ }^{1}$, Alexandra Boucher ${ }^{2}$, Reynald Le Boisselier ${ }^{3}$, Sylvie Deheul ${ }^{4}$ and Danièle Debruyne ${ }^{3}$ \\ 1 Centre d'Addictovigilance de Poitiers, CHU, Poitiers, France \\ 2 Centre d'Addictovigilance de Lyon, CHU, Lyon, France \\ 3 Centre d'Addictovigilance de Caen, CHU, Caen, France \\ 4 Centre d'Addictovigilance de Lille, Faculté de médecine, Lille, France
}

Text received September $9^{\text {th }}, 2014$; accepted October $21^{\text {st }}, 2014$

\begin{abstract}
Keywords:
new drugs;

substituted

phenethylamines;

substituted cathinones;

methoxetamine;

synthetic cannabinoids

Abstract - New substances, also known as "designer drugs" or "legal highs" are increasingly available to drug users. Two hundred and fifteen hitherto unlisted substances have been notified by European Union member states since 2005. These synthetic drugs, which have been developed to side-step the legislation on drugs, are analogues or derivatives of existing drugs and medications. The availability of these "legal highs", sold on Internet under various denominations such as bath salt, plant fertilizer, chemical not intended for human use, or spice, is unlimited. The effects felt by users vary, and the substances may be stimulant, entactogenic, hallucinogenic, psychedelic or dissociative. The pharmacological targets also vary, and may be either the increase of extracellular levels of neurotransmitters via different mechanisms (reuptake inhibition, stimulation of intracellular release) or else fixation on specific receptors. Several chemical classes, themselves divided into sub-classes, are involved: phenethylamines, tryptamines, piperazines, cathinones, cannabinoids etc. The toxicity of the main members of these categories is increasingly well known, the most deleterious being behavioural effects, physical manifestations, and cardiovascular consequences. However, small variations in their chemical structure can generate effects that are quantitatively different, thus enhancing their toxicity or addictive potential, and much remains to be achieved in terms of knowledge about these new drugs. These substances are indeed present on the French territory, as shown by data provided by the Observatoire Français des Drogues et Toxicomanies, and notifications by the French Addictovigilance network. Screening in clinical toxicology laboratories is not widespread, since these molecules are not detected by the standard screening tests, so that there is probably an under-estimation of the use of these new drugs. The legislation on these substances changes regularly, with more and more countries classifying them as "narcotics" or illegal psychotropic drugs so as to restrict their use, applying a generic classification when possible.
\end{abstract}

Abbreviations: see end of article.

\section{Introduction}

In the last decade, new synthetic substances with psychoactive effects have appeared on the drugs market, for different reasons, among which firstly the reduced availability or poorer quality of the "classic" drugs like heroin, cocaine or ecstasy, secondly the appearance and development of "free parties", thirdly the quest for stimulants and entactogens that mimic the effects of ecstasy or cocaine and are designed for these festive venues (party pills, funk pills), and fourthly the spectacular development of information and sales websites. These synthetic "designer drugs" have been created to side-step existing legislation, and are thus known as "legal highs". They are most often analogues, or are derived from existing drugs and medications, obtained by variously altering their chemical structure (and termed "research chemicals"). These new drugs are related to numerous different chemical classes: phenethylamines, tryptamines, piperazines, cathinones, cannabinoids etc, which are in turn divided into subclasses each comprising numerous items. Indeed, the general mode of development of these substances consists in starting from the basic structure of a group, often natural, and exploring all the possible additions of radicals so as to create a host of derived substances. These substances are nevertheless not necessarily new, as a number of these synthetics have been described, for instance by Alexander and Anne Shulgin in the books "PiHKAL" ${ }^{[1]}$ and "TiHKAL" [2] published in 1991 and 1992 respectively, or by John 
William Huffman whose research in the 1980s was centred on the identification of endo-cannabinoid receptors. ${ }^{[3]}$ These drugs can be obtained via commercial websites under various appellations, such as "bath salts" or "plant fertilizer", which have no real relationship with the actual purpose of the substance, and under more generic commercial names like "herbal essences", "Ivory Wave", "NRG" etc, or again under the international nonproprietary names (INN) for chemical substances with the proviso "not intended for human use". These drugs are now part of the range of substances offered by street dealers. None of these different appellations, however precise, guarantees the nature of the substances purchased or its exact composition, and mixes are frequently observed in samples analysed.

In vitro, the pharmacological targets are varied 1) mostly aiming to enhance the synaptic concentration of monoamines by way of different mechanisms of reuptake or release from storage sites (concentrations of these catecholamines, among which dopamine, serotonin, or norepinephrine, affect the hallucinogenic, toxic or addictive potential of the drug in different ways), and 2) also contributing to the activation of specific receptors, such as the central cannabinoid receptors type $1(\mathrm{CBI})$ that are liable to the euphoric effects of cannabinoid drugs.

In vivo, in animals, with the exception of cannabinoids the new drugs usually enhance locomotor activity to a variable degree and for variable durations. They are also involved in the regulation of motor coordination, memory and thermo-regulation. The greatest risk is cardiovascular.

In humans, the felt effects vary, and include stimulant/relaxant, entactogenic, hallucinogenic, psychedelic and dissociative effects. The toxicity of these substances is increasingly well mapped-out, and entails behavioural effects (anxiety, psychosis, violence) and physical manifestations (hyperthermia, rhabdomylosis, cardio-vascular accidents). The care provision for these patients is above all symptomatic, which is reinforced by the fact that diagnosis of poisoning by one or other of these new drugs is not easy to establish. Their screening is not usual in ordinary analysis laboratories, because these molecules do not fit into classic screening tests. In clinical or forensic laboratories, the ability to obtain reference solutions from highly reactive suppliers has enabled a rapid updating of the analysis libraries, and the documentation of medical or forensic cases. However the fairly unspecific mass spectra and frequently low concentrations in biological fluids, entailing the need for sophisticated equipment, as well as the constant arrivals of new substances, make analysis difficult and time-consuming. ${ }^{[4,5]}$

Two hundred and fifteen new substances have been notified via the EU member states Early Warning System since 2005, of which 46 in 2011 and 73 in 2012, so that they have become a key phenomenon in drug use in Europe. ${ }^{[6]}$ Likewise, in the French

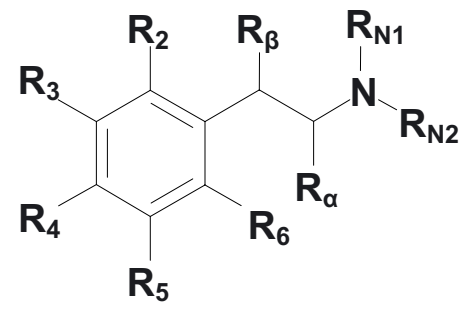

Fig. 1. Structure of substituted phenethylamines.

Addictovigilance networks and Poison Control centres, as well as in forensic toxicology laboratories, since the first instances of use of these drugs in the years following 2010, other notifications have corroborated the use of these substances on French national territory.

The majority of EU states, aware of the public health issues raised by the arrival of these new drugs, have taken energetic measures to assess and contain the propagation of this phenomenon. The legislation concerning these substances has consequently evolved, with more and more countries deciding to monitor and limit their use in their territories. Thus in France, the health and sports Minister decided to classify the following as "narcotics": several cannabinoids in 2009, mephedrone in 2010, 4-fluoroamphetamine in 2011, the cathinone family and 4methylamphetamine in 2012, methoxetamine in 2013 and 5-IT in 2014.

The aim of this paper is to set out present knowledge about the substances that have most concerned health authorities in recent years, with particular emphasis on the specific features of each new drug or group of drugs.

\section{Substituted amphetamines type 4-FA (4-fluoroamphetamine) and 4-MA (4-methylamphetamine)}

Substituted phenethylamines (figure 1) include a wide range of drug and medication classes, among which amphetamines and methamphetamines are certainly the most popular. In chemical terms, 4-fluoroamphetamine (4-FA) and 4-methylamphetamine (4-MA) only differ from amphetamine by the presence, in the para position (position 4) of the aromatic ring, of a fluorine ion for the former and a methyl group for the latter. 4-FA and 4MA are therefore phenethylamines that are structurally close, but present different pharmacological profiles, thus exemplifying the variability of the structure/activity relationship of substituted amphetamines. 


\subsection{4-FA}

The D-isomer of 4-FA possesses amphetamine-like effects: it inhibits monoamine oxidases $\mathrm{A}$ and $\mathrm{B}$, stimulates the release of neuromediators (norepinephrine, serotonin, dopamine) and inhibits their reuptake. ${ }^{[7-10]}$ The effects of 4-FA are however less powerful than those of D-amphetamine or Dmethamphetamine in Squirrel monkeys. ${ }^{[7]}$ In rats, compared to methylenedioxymethamphetamine (MDMA), 4-FA causes a similar release of dopamine and serotonin, more strongly inhibits the reuptake of dopamine, and less so the reuptake of serotonin. ${ }^{[10]}$

From the clinical viewpoint in humans, the effects reported by users on Internet forums are amphetamine- and MDMA-like stimulant effects, in line with experimental studies in rats. ${ }^{[11]} \mathrm{A}$ Dutch study carried out in 2010 and 2012 among ecstasy pill users attempted to link effects experienced "blind" by users to the composition of the pills. Among the 35 users who actually took 4FA, $60 \%$ enjoyed the effects, which they described as comparable to those experienced with MDMA. ${ }^{[12]}$ Negative effects have less often been described. They include irritability, dizziness, nausea, sweating, bruxism, palpitations, deformed vision, cold extremities sensations, and tinnitus. Comedown effects are also reported: asthenia, weakness, depressed mood, irritability, panic attacks, nausea, vomiting, tachycardia, sweating, myalgia, anorexia and sleeplessness, the last two liable to a duration from 12 hours to several days. Acute toxicity has been little reported: only three deaths have been reported, two in the UK in 2010 and 2011 and one in Denmark in 2009. ${ }^{[13]}$ 4-FA may have been implicated in one case; it was evidenced among other substances in the second, and associated with methadone, amphetamine and benzodiazepines in the third. The long-term toxicity of 4-FA is not known.

Experimental data involving self-administration in rhesus monkeys found an abuse potential of the amphetamine type. ${ }^{[14]}$ In rats, discrimination tests showed complete substitution for fenfluramine and amphetamine, but not for N-methyl-1(1,3-benzodioxol-5-yl)-2-butanamine (MBDB) or 5-methoxy-6methyl-2-aminoidane (MMAI). ${ }^{\text {[9] }}$ Some users describe signs of tolerance, and a few instances of abuse have been reported.

It is used by "initiates" under the appellations 4-FA, 4-FMP, Flux, Xenon, BongBastic, etc... in recreational or festive settings for purposes of stimulation, creativity, sociability, dancing, or to obtain a "MDMA effect": in 2008, in Slovenia, 4-FA was quoted as being one of the most popular "designer drugs" on the "electro scene". It is also to be found in samples supposed to contain amphetamine or MDMA.

Given its pharmacological properties, the fact that its effects and toxic risks are close to those of amphetamine or MDMA, its abuse potential of the amphetamine type and its rapid spread through Europe (a dozen countries) and in France, 4-FA has been classified as an illegal drug in France since March $16^{\text {th }}, 2011$.

\subsection{4-MA}

After being the subject of a few clinical studies performed and later abandoned in the 1950s which aimed to characterise its anorectic effects, 4-MA is at present known to users under the names 4-MA, PAL 313, p-methylamphetamine, Aptrol, p-TAP etc.

In vitro, the dopamine release resulting from 4-MA is similar in scale to that of amphetamine and 4-FA. ${ }^{[15]}$. As it also releases serotonin similarly to fenfluramine, 4-MA is described as non-selective in terms of dopamine versus serotonin release. ${ }^{[15]}$ By comparison, the release potential for serotonin derived from amphetamine and 4-FA is low, which places these two substances in the family of highly selective substances for dopamine release versus serotonin release. ${ }^{[15]}$ In vivo, in micro-dialysis in monkeys, 4-MA proves to be less dopaminergic than amphetamine, on the other hand other hand, it provides a strong stimulation for serotonin release in rats. ${ }^{[15,16]}$ Regarding behaviour, in rats and monkeys it has anorectic effects comparable to those of Damphetamine, it increases locomotor activity very little or not at all, and has low positive reinforcement potential. ${ }^{[14,16,17]}$

In humans, in a clinical study implemented in 1950, at doses of 1.5 and $2 \mathrm{mg} / \mathrm{kg}$, anorexia, sweating, nausea and vomiting, elevated blood pressure, hypersialosis, abdominal pain, cough and bronchorrhea were all observed. ${ }^{[18]}$ In its report on the evaluation of risks linked to 4-MA in 2014, the European Monitoring Centre for Drugs and Drug Addiction (EMCDDA) reported 20 cases on non-fatal acute toxicity in 5 European countries, and 21 cases of death backed up by toxicology analyses, having occurred in Belgium, Denmark, Netherlands and UK since 2010. ${ }^{[19]}$ In three cases the reported symptoms before death included one pseudoinfluenza syndrome, one major hyperthermia, agitation, a "sensation of heat" and "involuntary jerks". ${ }^{[20]}$ In the large majority of cases there was an association with amphetamine. These effects can be set against those observed in mice at a dose of $136 \mathrm{mg} / \mathrm{kg}$ (DL50): sympathomimetic symptoms and acute lung oedema. ${ }^{[18]}$

On Internet forums, the reports from 4-MA users mainly note stimulant effects, which are described as strong, but above all negative effects. 4-MA appears not to be widely used, contrasting with its considerable presence on the drugs market, as deduced from the numerous drug seizures across Europe (17 countries). Among the cases of intoxication quoted earlier, two users thought they were taking amphetamine, one other thought it was ketamine and, in addition, in Germany 4-MA has been identified in $11 \%$ of amphetamines. ${ }^{[21]}$ These elements suggest a contamination of 
amphetamine market, with users unknowingly taking 4-MA. Although the mechanisms underpinning its toxicity are not completely established, in animals 4-MA has been shown to have a serotoninergic activity. In humans, cardiovascular effects, even at low doses, have been observed, exposing an unwitting user to real toxicity. For these reasons, and despite the fact that its abuse potential is considered theoretically to be lower, on account of its ability to release less dopamine and more serotonin, it has been classified as an illegal drug in France on September 10 ${ }^{\text {th }} 2012$, and in the European Union from March $7^{\text {th }} 2013$.

These two substituted amphetamines, 4-FA and 4-MA, are a perfect illustration of the problem of the new drugs, used without knowledge of their nature, effects and toxicity, and rapidly spreading over large territories, contaminating the drugs market without users being aware.

\section{Phenethylamines types $2 \mathrm{C}-\mathrm{X}$ and $25 \mathrm{X}-\mathrm{NBOMe}$}

In the large phenethylamine or phenylethylamine family, $2 \mathrm{C}$ $\mathrm{X}$ and 25X-NBOMe form a distinct group, the main member being 4-bromo-2,5-dimethoxyphenylethylamine (2C-B), considered as a hallucinogenic, psychedelic drug. The addition on the benzene ring of methoxy- groups in positions 2 and 5 provides a series of compounds of the $2 \mathrm{C}$-X type, with a structure close to that of mescaline. The variety of these molecules results from the nature of the lipophile substitute $X$ in position 4 of the benzyle ring. The addition of a methoxybenzyl group on the nitrogen of a 2C-X compound finally yields its 25X-NBOMe analogue (or 2C-X-NBOMe). Ten of these were listed at the end of 2013 (figure 2). ${ }^{[22]}$

These 2C-X, which were synthesised in the 1970s and 1980s by A. Shulgin, only really gained popularity at the end of the 1990s, after the publication of his book PiHKAL. ${ }^{[1,23]}$ Either on their own or in association with other phenethylamines, these compounds are still present on the international scene, but there has been an evolution in the nature of the $2 \mathrm{C}-\mathrm{X}$ identified, with $2 \mathrm{C}$-E or $2 \mathrm{C}$-I replacing $2 \mathrm{C}-\mathrm{B}$ or $2 \mathrm{C}-\mathrm{T}-2 .{ }^{[24]}$ The spread was more rapid with their 25X-NBOMe analogues. These were synthesised for neurobiological research purposes in the years after 2000, and the first reports of identifications on the drugs market occurred after 2010, rapidly followed by reports of the first cases of intoxication and death. ${ }^{[25]}$ Like other new synthesised substances, they are mainly offered for sale on the Internet, which is an important factor in their dissemination. The three compounds most often found on websites are 25B-NBOMe, 25C-NBOMe and 25I-NBOMe. ${ }^{[25]}$<smiles>[X]c1cc(OC)c(CCN)cc1OC</smiles>

2C-B; $\mathrm{X}=\mathrm{Br}$ 2C-C; $\mathrm{X}=\mathrm{Cl}$ 2C-E; $\mathrm{X}=\mathrm{C}_{2} \mathrm{H}_{5}$ 2C-I; $X=I$ 2C-P; $\mathrm{X}=\mathrm{C}_{3} \mathrm{H}_{7}$ 2C-T-2; X $=\mathrm{SC}_{2} \mathrm{H}_{5}$ 2C-T-7; X $=\mathrm{SC}_{3} \mathrm{H}_{7}$<smiles>[X]c1cc(OC)c(CCNCc2ccccc2OC)cc1OC</smiles>

25B-NBOMe; $\mathrm{X}=\mathrm{Br}$ 25C-NBOMe; $\mathrm{X}=\mathrm{Cl}$ 25E-NBOMe; $\mathrm{X}=\mathrm{C}_{2} \mathrm{H}_{5}$ 25I-NBOMe; $X=$ I

Fig. 2. Structure of substituted phenethylamines types 2C-X and 25X-NBOMe.

The 2C-X have marked affinities for serotoninergic receptors type 5- $\mathrm{HT}_{2 \mathrm{~A}}$ and $5-\mathrm{HT}_{2 \mathrm{C}}$, on which they have an agonist or antagonist effect according to the subtype of receptor involved. Some are also partial agonists for $\alpha 1$-adrenergic receptors. ${ }^{[26]}$ Their action on the reuptake and release of monoamines however appears weak compared to other derived substances of the phenethylamine type. ${ }^{[10]}$ In $25 \mathrm{X}-\mathrm{NBOMe}$ compounds the addition of the methoxybenzyl radical imparts an affinity for $5-\mathrm{HT}_{2 \mathrm{~A}}$ receptors which is markedly stronger than that observed for their $2 \mathrm{C}-\mathrm{X}$ analogues, leading to potent partial (25B- and 25C-NBOMe) or complete agonists (25I-NBOMe). ${ }^{[22,27,28]}$

2C-X compounds and their 25X-NBOMe analogues are used for their hallucinogenic properties. They also have stimulant properties. The usual doses with $2 \mathrm{C}-\mathrm{X}$ are around ten to several tens milligrams, with effects that are mainly stimulant at low doses - generally less than $10 \mathrm{mg}$ per os - while the psychedelic effects appear at higher dosages. It is important to underline that the boundary between effects said to be slight and a genuine overdose is very narrow. ${ }^{[26]}$ These substances are most often found in the form of powders or pills, taken orally or nasally. Generally, the effects are felt within 1 to 3 hours after intake, and last 5 to 7 hours. The time lapse to reach effect and the duration of effect are shortened in case of nasal intake. ${ }^{[26,29]}$ The 25X-NBOMe compounds for their part are mainly found in the form of blotting papers (oral or sublingual use). They are found less frequently as a powder (nasal inhalation) or liquid (nasal inhalation or injection. ${ }^{[22,27,28,30]}$ The doses required are far smaller than with $2 \mathrm{C}-\mathrm{X}$ under one milligram - which increases the risk of overdose. ${ }^{[26,31]}$

Information on the toxicity of these substances is provided by case descriptions in the literature. Typically a toxic syndrome (or toxidrome) of the sympathomimetic type is observed (unlike what occurs with lysergic acid [LSD], for which these substances 
are sometimes substitutes) possibly accompanied by serotoninergic signs. From a somatic point of view, the clinical profile may involve tachycardia, hypertension, mydriasis, hyperthermia, myclonic jerks or even convulsions, metabolic acidosis, rhabdomyolosis and renal failure (in particular with the 25X-NBOMe). The psychiatric profile is dominated by agitation that is sometimes marked, with delusions - whether or not accompanied by aggressiveness - and visual and auditory hallucinations. In the absence of a specific antidote, the care provision for $2 \mathrm{C}-\mathrm{X}$ or $25 \mathrm{X}-\mathrm{NBOMe}$ intoxication is merely symptomatic, involving in particular sedation using benzodiazepines as the first line treatment. ${ }^{22,27,28,32-35]}$ Intoxications can be severe, and deaths have been related to $2 \mathrm{C}$ T-7 ${ }^{[23,36]}$ and 2C-E. ${ }^{[37]}$ Concerning 25X-NBOMe, several deaths have also been reported, particularly involving 25I-NBOMe, this being so despite the recent appearance of these drugs on the market. World Health Organization (WHO) has reported over twenty deaths as a result of using 25X-NBOMe, the majority being attributed to acute overdose. Other deaths are termed indirect, and linked to behavioural causes (self-inflicted injuries, drowning etc.). ${ }^{[22,27,28,38]}$

In France few cases have been confirmed by the Addictovigilance network, although a handful of cases involving 25X-NBOMe are considered likely on account of the symptoms presented and/or the reports by the users, but no confirmation analysis has been possible. Under-reporting is therefore very probable, on account of the analysis problem (concentrations are very low in biological fluids), but also on account of the fact that these substances may be on offer under different appellations, which maintains a considerable degree of confusion. It is for instance known that $2 \mathrm{C}-\mathrm{B}$ or $2 \mathrm{C}-\mathrm{E}$ have been sold as ecstasy, $2 \mathrm{C}-\mathrm{I}$ as mescaline, and these substances can be found adulterating other illicit drugs. ${ }^{[28,39]}$ The 25X-NBOMe compounds may also be sold as LSD, mescaline, ecstasy or as $2 \mathrm{C}-\mathrm{B}$ or $2 \mathrm{C}-\mathrm{E} .{ }^{[30,40]}$ The presence of these substances in France is however well established, with seizures and formal identification of several since 2010 ${ }^{\text {[41] }}$ and in 2013 with the closure of an illegal laboratory packaging 25C-NBOMe and 25I-NBOMe in Brittany. ${ }^{[42]}$

Like other new synthetic substances, the $2 \mathrm{C}-\mathrm{X}$ compounds, followed by the $25 \mathrm{X}-\mathrm{NBOMe}$, have taken the place of other substances already classified as illegal, and 25I-NBOMe compounds are sometimes presented as a "legal alternative" to LSD. From 2001, only 2C-B has been listed on Schedule II of the Convention on Psychotropic Substances. ${ }^{[43]}$ The legal status of the $2 \mathrm{C}-\mathrm{X}$ and the 25X-NBOMe compounds varies from one country to the other. Recently the increasing number of seizures and reports of serious cases of intoxication with 25X-NBOMe substances have led international health authorities to assess these molecules from a pharmacological, toxicological and epidemiological viewpoint. However several countries inside and outside Europe have already

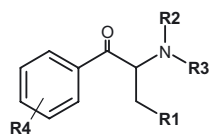

(a)

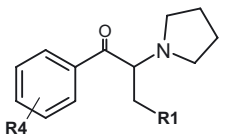

(b)

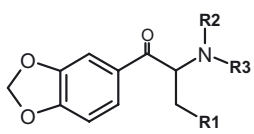

(c)
Fig. 3. Chemical structure of substituted cathinones.

adopted measures applying to the 25X-NBOMe compounds. The UK, following a temporary regulatory measure in June 2013, has validated the permanent classification of all 25X-NBOMe compounds as narcotics, with one exception for 25I-NBOMe, a radioactive substance used as a tracer in medical imaging. Likewise, at the end of 2013 the United States adopted a measure of temporary controlled status for 25I-NBOMe, 25C-NBOMe and 25BNBOMe. In France to date, only 2C-B, 2C-I, 2C-T-2 and 2C-T-7 have been classified as illegal drugs.

\section{Cathinones}

Synthetic cathinones are a large family of substances derived from cathinone, an alkaloid that is naturally present in khat, and differing from amphetamine solely by the presence of a ketone function on the beta carbon of the aliphatic chain, hence its appellation beta-keto phenethylamine. From this basic structure, numerous compounds have been synthesised by modifying the substitutes located on four possible positions, R1, R2, R3 and R4 (figure 3). These radicals can be simple groups of the alkyl, alcoyl, halogen, haloalkyl or phenyl type. Nitrogen can be inserted in a ring (figure $3 \mathrm{~b}$ ) producing numerous pyrrolidinyl derivates. A methylenedioxy ring can be added to the phenyl ring (figure $3 \mathrm{c}$ ) and form a family of ketone equivalents of methylenedioxy amphetamines and methamphetamines of the types MDMA (ecstasy), MDEA, MBDB etc. ${ }^{[4]}$

Simpler appellations are often used for these compounds instead of their chemical names, such as street names or not very informative generic names. Thus 4-methylmethcathinone, the first substituted cathinone class leader having alerted authorities, can be sold under the names mephedrone, miaou-miaou, meow-meow, Energy 1, NRG1, bath salt, plant fertilizer etc. ${ }^{[45]}$

Substituted cathinones act as stimulants of the central nervous system (CNS) by increasing synaptic concentrations of monoamines such as dopamine, serotonin and norepinephrine. They act by inhibiting the reuptake transporters, and also by stimulating the release of the three monoamines from the intracellular storage locations. However, in in vitro tests there are differences that are both qualitative and quantitative between the results obtained in terms of inhibition of reuptake and stimulation of release, depending on the substituted cathinone considered. Thus mephedrone, like methamphetamine, acts in non-selective 
manner on transporters, and mainly releases dopamine and serotonin. ${ }^{[46,47]}$ In contrast, and in a similar way to cocaine, pyrrolidinyl cathinones do not cause a release of dopamine and serotonin, but specifically block their transporters. ${ }^{[46,48]}$ In vivo, substituted cathinones increase locomotor activity, inhibit food intake, and have an effect on motor coordination and thermoregulation. Their toxicity is correlated with their action on the transporters. ${ }^{[49]}$ In animal dependency models, they show reinforcement properties. ${ }^{\text {[50] }}$

In humans, substituted cathinones, which are generally taken orally or sniffed, even injected in gay men, stimulant and entactogenic properties. ${ }^{[51]}$ The dose taken varies according to the substance, from a few milligrams to several tens of milligrams. Their effects include euphoria, intensification of sensations, mental stimulation, enhanced sociability, empathy and sexual excitation. The physical signs of intoxication the most frequently observed are agitation, tachycardia, palpitations, arrhythmia, increased blood pressure, bruxism, loss of appetite, headache, and hyperthermia. ${ }^{[52]}$ In case of major overdose, rhabdomyolysis, hyponatraemia, acidosis and convulsions can lead to cardiorespiratory collapse, myocardial infarct, cerebral oedema, multi-organ failure and death. ${ }^{[53-55]}$ Behavioural effects include insomnia, agitation, confusion, panic attacks, hallucinations, suicidal ideations, self-mutilation, violent and aggressive behaviours. In case of overdose, and because there is no specific antidote, medical care is once again mainly symptomatic, and mainly based on the experience derived from the treatment of cocaine or amphetamine intoxication. ${ }^{[44]}$ Numerous cases of mephedrone dependency have been described in the literature. ${ }^{[56]}$ All these effects vary quantitatively from one cathinone to another with the intensity of the dopaminergic and/or serotoninergic effects of the substances. ${ }^{[57]}$

The legal status of cathinones and their derivatives varies from country to country, and has evolved rapidly in the last decade, providing a good illustration of the issue of classification of these new drugs. Some drugs, listed in group 1 of the United Nations convention on psychotropic substances, such as cathinone and methcathinone, or in group 4, like amfepramone and pyrovalerone, have been under international control for many years. Regarding the new molecules appearing on the market, very few had illegal status in Europe before 2007. From that date, on account of the public health problems raised by these substances, the EU member states reacted fast, taking regulatory measures to limit their use. Thus between 2007 and 2010, after the UK which was one of the first countries to be confronted with fatalities linked to mephedrone, 14 European countries including France, followed by the European Council in 2010, banned the use of mephedrone in their territories. Methylone, made illegal in 7 European countries by 2011, became illegal in 19 in 2012. However, since new synthetic cathinones, presented as legal drugs by retailers and considered as such by users, were arriving on the market, and as the individual classification of each molecule was becoming impracticable, other policies were required to try to restrict the diffusion of these substances. Because the particular feature of this class of new drugs is that it includes a large number of items, all derived from the same basic structure, the French health authorities, in the wake of the UK, established the first generic classification of a chemical family, associating a lead substance to a series of potential derivatives.

\section{Methoxetamine}

Methoxetamine (MXE), or 2-(3-methoxyphenyl)-2-(ethylamino)cyclohexanon, belongs to the arylcyclohexylamine family, with a structure close to ketamine, and also to phencyclidine (PCP) and tiletamine. These substances have been or are still used as human and/or veterinary anaesthetics, but they are also misused, so that they are classified as dissociative drugs. ${ }^{[58]}$

MXE appeared on the Internet in 2010 under the names M-Ket, Kmax, Mexxy or Special M (Special K being one of the names given to ketamine). It was offered as a substance for "chemical research", synthesised for the purpose of side-stepping the legislation on drugs, which earned it its nickname of "legal ketamine".

Because of its chemical similarities with ketamine and the shared recreational effects observed, MXE was first of all thought to act a) as an antagonist of NMDA receptors, explaining its dissociative properties and b) as an inhibitor of dopamine reuptake, explaining is euphoric effects. ${ }^{[59,60]}$ In vitro, these hypotheses on the mechanisms appear to be only partly confirmed, since MXE does indeed exhibit affinity with NMDA receptors, but no affinity at all for dopamine transporters or receptors. ${ }^{[61]}$ It does however exhibit affinities with serotonin transporters, which could explain, at least in part, certain serotoninergic clinical signs observed among users (agitation, trembling, hyperthermia). ${ }^{[61]}$ It effects on NMDA receptors have led certain authors to consider that MXE might, like ketamine, have an antidepressant effect, but no study enabling this to be confirmed or otherwise has been implemented. ${ }^{[62]}$

Intake of this substance is mainly nasal or oral, but cases of intramuscular or intravenous injection have also been reported. ${ }^{[59,63]}$ The doses used range from 20 to $100 \mathrm{mg}$ orally and 10 to $50 \mathrm{mg}$ in intramuscular administration, but doses can reach more than $100 \mathrm{mg}$ among patients who have become tolerant of the effects of the substance. ${ }^{[60]}$ MXE differs from ketamine by the time lapse before it acts and the duration of the effects. The effects seem to appear later (after 30 minutes) than with ketamine (less than 10 minutes) so that there is a risk of repeat administrations among users who are accustomed to the use of ketamine. 
However the effects last longer, 5 to 7 hours compared to 3 hours for ketamine. In intramuscular injection, the effects appear faster (5 minutes) and the duration of the effects is shorter (1 hour). ${ }^{[60]} \mathrm{A}$ recent in vitro study using human hepatic microsomes identified numerous MXE metabolites, also found in the urine of patients presenting acute MXE intoxication. ${ }^{[64,65]}$

The first case reports of the use of this molecule were published at the end of 2011, and they described effects similar to those observed with ketamine, i.e. a dissociative state with detachment of body and mind, leading some users to experiment with imminent death experiences. ${ }^{[66,67]}$ The effects sought also include euphoria, empathy, and a pleasant intensification of sensory experiences, in particular music. ${ }^{[68]}$ Nevertheless, these effects are often accompanied by negative effects like visual hallucinations, trembling, confusion, agitation or somnolence and memory loss. Users also regularly present signs of sympathomimetic toxicity, generally with elevated blood pressure and tachycardia. ${ }^{[59,67]}$ Cerebellar toxicity with dysarthria can occur, accompanied by unsteady gait, nystagmus etc. ${ }^{[69]}$ Medical care of acute MXE intoxication is based on symptomatic treatment with benzodiazepines in case of agitation and hypertonia, and with beta-blockers in case of sympathomimetic toxicity. The patient requires surveillance for at least 24 hours on account of the long duration of the effects of the substance (specified in a note to emergency departments in France in July 2013). One case of fatal intoxication has been described in Sweden, for a patient found dead in his home whose autopsy evidenced pulmonary oedema. ${ }^{[70]}$ The case of the death of a man aged 38 , with a post-mortem analysis confirming a concentration of MXE of over $9 \mu \mathrm{g} / \mathrm{mL}$, was reported by the Addictovigilance network in France: diffuse traumatic lesions and a bitten tongue suggested extreme agitation at the time of death, or possibly a convulsive episode. Further to this, MXE is reputed on forums to be "bladder-friendly", that is to say presenting lower toxicity for the bladder and gall bladder than ketamine. The lack of sufficient experience of this substance means that the hypothesis cannot be confirmed, all the more so because in a recent study this type of toxicity was observed in mice after administration of MXE for three months. ${ }^{[71]}$

Finally, concerning addictive potential, the structural analogy with ketamine suggests the risk of mental dependency, and the development of tolerance. Certain remarks by users on the Internet do indeed report compulsive behaviours in the use of MXE.

The use of this substance appears to have developed in the last three years, as suggested by the increasing number of case reports on problematic use of MXE across the world. ${ }^{[59,66,67,69]}$ Likewise, in studies evaluating substances found in seizures during legal investigations $^{[72]}$ or identifying substances found in the urinals in London, ${ }^{[73]} \mathrm{MXE}$ is regularly quoted. It is also regularly found, as are other new synthetic drugs, as a cutting agent in MDMA, amphetamine, ketamine or cocaine. ${ }^{[74]}$ In France, 13 cases of use of MXE between 2011 and February 2013 were notified to the French Addictovigilance network.

This increasing usage, coupled with the established dangerousness of the substance, has led to the classification of MXE as an illegal drug in numerous countries (Switzerland, Russia, the UK, etc). In France, MXE was added to the list of narcotic substances in August 2013.

\section{Synthetic cannabinoids}

Synthetic cannabinoids (SCs) are molecules that were developed from the 1970s for fundamental research, and have proved useful in the exploration of cannabinergic pharmacological pathways.

Like $\Delta 9$-tetrahydrocannabinol (THC), the main substance behind the central effects of cannabis, and in the same manner as the endogenous ligands (mainly anandamide and 2arachydonylglycerol), the SCs have a varying degree of affinity for the two types of cannabinoid receptors, $\mathrm{CB} 1$ and $\mathrm{CB} 2$. CB1 receptors are mainly present in the central ${ }^{[75,76]}$ or peripheral ${ }^{[77]}$ nervous system, but it has been shown that they are also expressed in certain peripheral tissues such as heart, liver, pancreas, skeletal muscle and reproductive system. ${ }^{[78,79]} \mathrm{CB} 2$ receptors for their part are expressed mainly in the immune system. ${ }^{[79]}$ The endocannabinoid system is thus implicated in numerous physiological functions (reward system, memory, nociception, cardiovascular system, immune system etc.), which exposes users of these substances to numerous harmful effects.

SCs, selected for their affinities with CB1 receptors, were evidenced for the first time for their use in recreational settings in December 2008 by a German firm who identified them in packages of plants to be smoked, with an attractive presentation and carrying names such as "Spice", "Yucatan", "Chill", "K2", or "Black mamba". To restrict health risks, following analysis of pharmacological and health issues by the National Commission on Psychotropic Drugs, ${ }^{[80]}$ France very rapidly adopted regulatory measures, classifying as illegal drugs in February 2009 the first molecules detected across the world (JWH-018, CP-47, 497 and its analogues C6, C8, and C9, HU-210). ${ }^{[81]}$ Since then, the number of cannabinomimetic substances identified in customs seizures has increased continually, as with other synthetic drugs. However, the issue of the classification of SCs, still the object of study, is problematic, as there is not just one class, but at least five main chemical classes:

- substances derived from the dibenzopyrane ring, which include classic cannabinoids and THC derivatives, and also, for instance, HU-210; 
- cyclohexylphenol derivatives: the CP 46,497 series and analogues;

- indole derivatives, comprising numerous subclasses: benzoylindoles (e.g. RCS 4, naphtoylindoles (e.g. JWH 018), phenylacetylindoles (e.g. JWH 250), naphtylmethylindoles (e.g. JWH 175), adamantoylindoles (e.g. AB-001) etc;

- pyrrole and naphtoylpyrrole derivatives (e.g. JWH 368);

- indene and naphtylindene derivatives (e.g. JWH 220).

This wide range of chemical classes, demonstrating the great flexibility of the ligand-receptor interaction, increases the difficulties encountered in terms of public health, starting with the challenge of the mere identification of these substances in analysis, whether on biological or non-biological samples. Indeed, the composition of preparations intended for smoking of the "Spice" type, when it can be determined, varies considerably, ${ }^{[82]}$ and the identification of the metabolic pathways of the SCs has barely started. ${ }^{[83]}$ The first identification kits for these substances have only recently appeared, and are necessarily incomplete. Thus at present, establishing a toxicological profile that is specific to each synthetic cannabinoid to enable targeted prevention among users is a real challenge.

However, from data that are now being published, in particular that derived from clinical case studies on users of K2 or "Spice" blends, a list of the most frequently reported effects in recreational use of SCs can be drawn up. First of all, there are the effects that are sought by cannabis users, transitory exhilaration, relaxation, well-being, alterations of the state of consciousness, hallucinations. It can be noted that in rodents SCs reproduce the "tetrad" of cannabinoid effects: this refers to a battery of four tests measuring analgesia, hypothermic potential, catalepsy and reduction in locomotor activity. Psychotic disturbances of the paranoid type, and signs such as anxiety, agitation, irritability, convulsions, fainting, nausea and vomiting and hypokalaemia can also be observed. Finally, alongside neuropsychiatric effects, ${ }^{[84-87]}$ cardiovascular effects have more recently been described, ${ }^{[84,88,89]}$ including tachycardia, palpitations, hypertension, chest pain, myocardial infarct, and one case of heart arrest in a patient with coronary disease.

Regarding tolerance, dependency and withdrawal symptoms, ${ }^{[90,91]} 3$ cases have been reported, in particular one concerning a 20-year-old man who rapidly increased his use of "Spice gold" to $3 \mathrm{~g}$ a day, who on days 4-7 of his hospitalisation presented signs of craving, with nightmares, sweating, trembling, headache, blood pressure at 180/90 $\mathrm{mmHg}$ and tachycardia (125 bpm).

Most of these effects have been described with cannabis, ${ }^{[92-94]}$ and are very probably linked to the activation of cannabinoid receptors. However there have been suggestions of an inhibiting effect, albeit minor, of monoamine oxydase, which exposes users to a theoretical risk of a serotoninergic syndrome at high doses. ${ }^{[95]}$

A study performed in 2011 in the UK on around 15000 individuals responding to an online-questionnaire designed to compare the use of cannabis versus the use of SCs evidenced a prevalence of experimentation with SCs of $17 \%$ in this population. SCs were described by users as reaching maximum effect faster, but as not lasting as long as natural cannabis. Most respondents (93\%) however reported a preference for cannabis which provided them with greater pleasure in large doses and was accompanied by fewer negative effects of the hangover or paranoia type. ${ }^{[87]}$ In the USA, a self-administered questionnaire including 2349 students found a similar prevalence for experimentation (14\%), well above that for cathinones (1\%). ${ }^{[96]}$

In conclusion, $\mathrm{SCs}$ seem to be drawing increasing interest, in particular in the English-speaking countries. These substances are undoubtedly the group of new synthetic drugs with the greatest structural diversity in the molecules, which makes their identification complex, whether for the customs authorities of for medical care. This diversity, much more so than for other synthetic substances, explains the unforeseeable nature of the damaging effects of the use of "Spice" or synthetic cannabinoids. ${ }^{[85]}$

\section{Conclusion}

The new psychotropic drugs that have appeared since 2010, relaying the "classic" illegal drugs, have the following characteristics:

a) wide range of substances available to users;

b) easy supply on websites;

c) variety of desired effects reported by users, mainly stimulant and entactogenic;

d) variety of modes of administration, above all oral and nasal with a faster onset of effect;

e) poor knowledge on the part of users of the nature and quantities of the substances used, as the actual content may or may not comply with its description;

f) proven toxicity for certain molecules, leading to public health problems;

g) structural differences, although sometimes slight, which can lead to alterations in the dopamine/serotonin balance with consequences in terms of toxicity and/or dependency;

h) diffusion across the national territory (here France) as evidenced from notifications to the Addictovigilance network;

i) under-estimation of usage, partly linked to hitherto inadequate means of analysis for screening;

j) potential therapeutic value; 
k) lack of homogeneity in legislation from one country to another, rapidly moving towards regulations aiming to restrict spread;

1) "fashion" effect for certain substances, and practically unlimited scope for producing novelties.

Although the recent literature has a wealth of research, in vitro, in vivo and behavioural in animals, as well as analytical studies on these new synthetic substances, the effects of intensive or chronic use in humans are still not well documented. The only data available is mainly based on user reports and isolated cases of medical observation, which are particularly difficult to interpret because it is also difficult to relate them to a clearly identified substance. The regulatory measures adopted by different countries to contain the use of these substances do not appear able to stamp out the phenomenon, which remains fairly difficult to apprehend. However, the diffusion of information on recognised harmful effects collected by different health networks could enable the health authorities to issue targeted messages towards the populations involved, and thus limit the risks linked to repeated experiments with the use of these numerous new drugs.

\section{Conflicts of interests. None.}

Abbreviations. 2C-B: 4-bromo-2,5-dimethoxyphenylethylamine; 4-FA: 4-fluoroamphetamines; 4-MA: 4-methylamphetamines; CB1: central cannabinoid receptors type 1; CNS: central nervous system; EMCDDA: European Monitoring Centre for Drugs and Drug Addiction; INN: international non proprietary names; LSD: lysergic acid; MBDB: N-methyl-1,3-benzodioxolylbutanamine; MDEA: 3,4-methylenedioxy-N-ethylamphetamine; MDMA: methylenedioxymethamphetamine; MMAI: 5-methoxy-6methyl-2-aminoindane; MXE: methoxetamine; SCs: synthetic cannabinoids; THC: $\Delta$ 9-tetrahydrocannabinol; WHO: World Health Organization.

\section{References}

1. Shulgin A, Shulgin A. PiHKAL: a chemical love story. Transform Press, Berkeley, California, 1991

2. Shulgin A, Shulgin A. TiHKAL: the continuation. Transform Press, Berkeley, California, 1997

3. Huffman JW. Cannabimimetic indoles, pyrroles, and indenes: structureactivity relationships and receptor interactions. In: Reggio Patricia H. (ed.). The cannabinoid receptors, Humana Press, Totowa, 2009

4. Al-Saffar Y, Stephanson NN, Beck O. Multicomponent LC-MS/MS screening method for detection of new psychoactive drugs, legal highs, in urineexperience from the Swedish population. J Chromatogr B Analyt Technol Biomed Life Sci 2013; 930: 112-20

5. Pedersen AJ, Dalsgaard PW, Rode AJ, et al. Screening for illicit and medicinal drugs in whole blood using fully automated SPE and ultra-highperformance liquid chromatography with TOF-MS with data-independent acquisition. J Sep Sci 2013; 36(13): 2081-9
6. EMCDDA, Rapport européen sur les drogues - tendances et évolutions. 2013 http://www . emcdda.europa.eu/attachements.cfm/att_213154_ FR_TDAT13001FRN_REV.pdf Accessed October $21^{\text {st }}, 2014$ (80 pages)

7. Yasar S, Gaal J, Justinova Z, et al. Discriminative stimulus and reinforcing effects of p-fluoro-L-deprenyl in monkeys. J Psychopharmacology 2005; 182(1): 95-103

8. Magyar K. Behaviour of (-)-deprenyl and its analogues. J Neural Transm Suppl 1994; 41: 167-75

9. Marona-Lewicka D, Rhee GS, Sprague JE, et al. Psychostimulant-like effects of p-fluoroamphetamine in the rat. Eur J Pharmacol 1995; 287(2): 105-13

10. Nagai F, Nonaka R, Satoh Hisashi Kamimura K. The effects of non-medically used psychoactive drugs on monoamine neurotransmission in rat brain. Eur J Pharmacol 2007; 559(2-3): 132-7

11. Rothman RB, Baumann MH. Balance between dopamine and serotonin release modulates behavioral effects of amphetamine-type drugs. Ann N Y Acad Sci 2006 Aug; 1074: 245-60

12. Brunt TM, Koeter MW, Niesink RJ, et al. Linking the pharmacological content of ecstasy tablets to the subjective experiences of drug users. Psychopharmacology 2012; 220(4): 751-62

13. Johansen $\mathrm{S}$, Hansen TM. Isomers of fluoroamphetamines detected in forensic cases in Denmark. Int J Legal Med 2012; 126(4): 541-7

14. Wee S, Anderson KG, Baumann MH, et al. Relationship between the serotoninergic activity and reinforcing effects of a series of amphetamine analogs. Pharmacol Exp Ther 2005; 313(2): 848-54

15. Baumann $\mathrm{MH}$, Clark RD, Woolverton $\mathrm{WL}$, et al. In vivo effects of amphetamine analogs reveal evidence for serotonergic inhibition of mesolimbic dopamine transmission in the rat. J Pharmacol Exp Ther 2011; 337(1): 218-25

16. Kimmel HL, Manvich DF, Blough BE, et al. Behavioral and neurochemical effects of amphetamine analogs that release monoamines in the squirrel monkey. Pharmacol Biochem Behav 2009; 94(2): 278-84

17. Wellman PJ, Davis KW, Clifford PS, et al. Changes in feeding and locomotion induced by amphetamine analogs in rats. Drug Alcohol Depend 2009; 100(3): 234-9

18. Marsh DF, Herring DA. The pharmacological activity of the ring methyl substituted phenisopropylamines. J Pharmacol Exp Ther 1950; 100(3): 298-308

19. EMCDDA. Report on the risk assessment of 4-methylamphetamine in the framework of the Council Decision on new psychoactive substances. OEDT 2014

http: //www . emcdda . europa.eu/publications/riskassessment/4-MA

Accessed October 21st , 2014

20. Belgian Early Warning System on Drugs: 4-methylamphetamine alert by EMCDDA https://ewsd.wiv-isp.be/Main/4Methylamphetamine\%20alert\%20by\%20EMCDDA . aspx Accessed October 21st , 2014

21. Blanckaert P, Van Amsterdam J, Brunt T, et al. 4-Methyl-amphetamine: a health threat for recreational amphetamine users. Psychopharmacol 2013 27(9): 817-22

22. World Health Organization. $36^{\text {th }}$ Expert Committee on Drug Dependence 25I-NBOMe Critical review report 2014 http://www . who.int/medicines/areas/quality_safety/4_19_ review.pdf Accessed October 21st , 2014 (24 pages)

23. EMCDDA. Report on the risk assessment of 2C-1, 2C-T-2 and 2C-T-7 in the framework of the joint action on new synthetic drugs. 2004 http: //www . emcdda. europa.eu/html.cfm/index33353EN.html Accessed October 21st, 2014 
24. US Department of Justice, Drug Enforcement Administration. Special report: emerging 2C-phenethylamines, piperazines, and tryptamines in NFLIS (National Forensic Laboratory Information System), 2006-2011. 2011 https://www.nflis.deadiversion.usdoj.gov/DesktopModules/ ReportDownloads/Reports/NFLIS_SR_Emerging_II.pdf Accessed October 21st , 2014 (8 pages)

25. Lawn W, Baratt M, Williams M, et al. The NBOMe hallucinogenic drug series: patterns of use, characteristics of users and self-reported effects in a large international sample. J Psychopharmacol 2014; 28(8): 780-8

26. Hill SL, Thomas SHL. Clinical toxicology of newer recreational drugs. Clin Toxicol (Phila) 2011; 49(8): 705-19

27. World Health Organization. $36^{\text {th }}$ Expert Committee on Drug Dependence. 25B-NBOMe Critical Review Report. 2014 http://www. who.int/medicines/areas/quality_safety/4_17_ review.pdf Accessed October 21st , 2014 (19 pages)

28. World Health Organization. $36^{\text {th }}$ Expert Committee on Drug Dependence. 25C-NBOMe Critical Review Report. 2014

http://www. who.int/medicines/areas/quality_safety/4_18_ review.pdf

Accessed October 21st , 2014 (19 pages)

29. Musselman ME, Hampton JP. "Not for human consumption": a review of emerging designer drugs. Pharmacotherapy 2014 Jul; 34(7): 745-57

30. EMCDDA-Europol: EMCDDA-Europol Joint Report on a new psychoactive substance: 25I-NBOMe. 2014

http://www. emcdda.europa.eu/publications/joint-report/ 25I-NBOMe

Accessed October 21st , 2014

31. Ninnemann A, Stuart GL. The NBOMe series: a novel, dangerous group of hallucinogenic drugs. J Stud Alcohol Drugs 2013; 74(6): 977-8

32. Tang MH, Ching CK, Tsui MS, et al. Two cases of severe intoxication associated with analytically confirmed use of the novel psychoactive substances 25B-NBOMe and 25C-NBOMe. Clin Toxicol 2014 Jun; 52(5): 561-5

33. Hill SL, Doris $\mathrm{T}$, Gurung $\mathrm{S}$, et al. Severe clinical toxicity associated with analytically confirmed recreational use of 25I-NBOMe: case series. Clin Toxicol (Phila) 2013; 51: 487-92

34. Prabhakar D. Exposure to potent hallucinogens in an adolescent: a case for high index of suspicion. Prim Care Companion CNS Disord 2013; 15(5)

35. Bosak A, LoVecchio F, Levine M. Recurrent seizures and serotonin syndrome following "2C-I" ingestion. J Med Toxicol 2013; 9(2): 196-8

36. Curtis B, Kemp P, Harty L, et al. Postmortem identification and quantitation of 2,5-dimethoxy-4-n-propylthiophenethylamine using GC-MSD and GCNPD. J Anal Toxicol 2003; 27(7): 493-8

37. Bronstein AC, Spyker DA, Cantelina LR, et al. 2011 annual report of the American Association of Poison Control Centers' National Poison Data System (NPDS): 29 ${ }^{\text {th }}$ Annual Report. Clin Toxicol (Phila) 2012; 50(10): 911-1164

38. Walterscheid JP, Phillips GT, Lopez AE, et al. Pathological findings in 2 cases of fatal 25I-NBOMe toxicity. Am J Forensic Med Pathol 2014; 35(1): 20-5

39. Giroud C, Augsburger M, Rivier L et al. 2C-B: a new psychoactive phenylethylamine recently discovered in Ecstasy tablets sold on the Swiss black market. J Anal Toxicol 1998; 22(5): 345-54

40. EMCCDA: European Drug Report. 2014.

http: //www . emcdda . europa . eu/publications/edr/trendsdevelopments $/ 2014$

Accessed October 21st , 2014

41. Nouveaux produits de synthèse identifiés en France depuis 2000 - note SINTES 2014.

http://www.ofdt.fr/BDD/sintes/ir_140831_nps.pdf Accessed October 21st, 2014 (2 pages)
42. Ladroue V, Besacier F, Hologne M. Découverte d'un laboratoire de conditionnement de nouveaux produits de synthèse en France. Ann Toxicol Anal 2013; 25(4): 175-84

http://www . ata-journal.org/articles/ata/pdf/2013/04/ ata130038.pdf

Accessed October 21st , 2014 (10 pages)

43. Organe international de contrôle des stupéfiants. Liste des substances psychotropes placées sous contrôle international.

http://www .incb.org/documents/Psychotropics/green_lists/ Green_list_FRE_2014_85223_GHB.pdf

Consulté le 21 octobre 2014 (36 pages)

44. Paillet-Loilier M, Cesbron A, Le Boisselier R, et al. Emerging drugs of abuse: current perspectives on substituted catrhinones. Subst Abuse Rehabil 2014; 5: $37-52$

45. Debruyne D, Courné MA, Le Boisselier R, et al. La méphédrone : une designer drug d'usage récent en France. Therapie 2010; 65(6): 519-24

46. Eshleman AJ, Wolfrum KM, Hatfield MG, et al. Substituted methcathinones differ in transporter and receptor interactions. Biochem Pharmacol 2013; 85(12): 1803-15

47. Simmler LD, Buser TA, Donzelli M, et al. Pharmacological characterization of designer cathinones in vitro. Br J Pharmacol 2013; 168(2): 458-70

48. Cameron K, Kolanos R, Vekariya R, et al. Mephedrone and methylenedioxypyrovalerone (MDPV), major constituents of "bath salts", produce opposite effects at the human dopamine transporter. Psychopharmacology (Berl) 2013; 227(3): 493-9

49. Sogawa C, Sogawa N, Ohyama K, et al. Methylone and monoamine transporters: correlation with toxicity. Curr Neuropharmacol 2011; 9(1): 58-62

50. Gatch MB, Taylor CM, Forster MJ. Locomotor stimulant and discriminative stimulus effects of "bath salt" cathinones. Behav Pharmacol 2013; 24(5-6): 437-47

51. Forrester MB. Synthetic cathinone exposures reported to Texas poison centers. Am J Drug Alcohol Abuse 2012; 38(6): 609-15

52. Prosser JM, Nelson LS. The toxicology of bath salts: a review of synthetic cathinones. J Med Toxicol 2012; 8(1): 33-42

53. Boulanger-Gobeil C, St-Onge M, Laliberté M, et al. Seizures and hyponatremia related to ethcathinone and methylone poisoning. J Med Toxicol 2012; 8(1): 59-61

54. James D, Adams RD, Spears R, et al. National Poisons Information Service. Clinical characteristics of mephedrone toxicity reported to the UK National Poisons Information Service. Emerg Med J 2011; 28(8): 686-9

55. Schifano F, Corkery J, Ghodse AH. Suspected and confirmed fatalities associated with mephedrone (4-methylmethcathinone, "meow-meow") in the United Kingdom. J Clin Psychopharmacol 2012; 32(5): 710-4

56. Johnson LA, Johnson RL, Portier RB. Current "legal highs". J Emerg Med 2013; 44(6): 1108-15

57. Wee S, Anderson KG, Baumann MH, et al. Relationship between the serotonergic activity and reinforcing effects of a series of amphetamine analogs. J Pharmacol Exp Ther 2005; 313(2): 848-54

58. Morris H, Wallach J. From PCP to MXE: a comprehensive review of the nonmedical use of dissociative drugs. Drug Test Anal 2014 Jul-Aug; 6(7-8): 614-32

59. Hofer KE, Grager B, Müller DM, et al. Ketamine-like effects after recreational use of methoxetamine. Ann Emerg Med 2012; 60(1): 97-9

60. Corazza O, Assi S, Schifano F. From "Special K" to "Special M": the evolution of the recreational use of ketamine and methoxetamine. CNS Neurosci Ther 2013; 19(6): 454-60

61. Roth BL, Gibbons S, Arunotayanun W, et al. The ketamine analogue methoxetamine and 3- and 4-methoxy analogues of phencyclidine are high affinity and selective ligands for the glutamate NMDA receptor. PLoS One 2013; 8(3): e59334 
62. Coppola M, Mondola R. Methoxetamine: from drug of abuse to rapid-acting antidepressant. Med Hypotheses 2012; 79(4): 504-7

63. Sein Anand J, Wiergowski M, Barwina M, et al. Accidental intoxication with high dose of methoxetamine (MXE): a case report. Przegl Lek 2012; 69(8): 609-10

64. Menzies EL, Hudson SC, Dargan PI, et al. Characterizing metabolites and potential metabolic pathways for the novel psychoactive substance methoxetamine. Drug Test Anal 2014; 6(6): 506-15

65. Meyer MR, Bach M, Welter J, et al. Ketamine-derived designer drug methoxetamine: metabolism including isoenzyme kinetics and toxicological detectability using GC-MS and LC-(HR-)MSn. Anal Bioanal Chem 2013; 405(19): 6307-21

66. Ward J, Rhyee S, Plansky J, et al. Methoxetamine: a novel ketamine analog and growing health-care concern. Clin Toxicol (Phil) 2011; 49(9): 874-5

67. Wood DM, Davies S, Puchnarewicz M, et al. Acute toxicity associated with the recreational use of the ketamine derivative methoxetamine. Eur J Clin Pharmacol 2012; 68(5): 853-6

68. Loeffler G, Craig C. Methoxetamine misuse and toxicity. J Stud Alcohol Drugs 2013; 74(5): 816-7

69. Shields JE, Dargan PI, Wood DM, et al. Methoxetamine associated reversible cerebellar toxicity: three cases with analytical confirmation. Clin Toxicol (Phila) 2012; 50(5): 438-40

70. Wikström M, Thelander G, Dahlgren M, et al. An accidental fatal intoxication with methoxetamine. J Anal Toxicol 2013; 37(1): 43-6

71. Dargan PI, Tang HC, Liang W, et al. Three months of methoxetamine administration is associated with significant bladder and renal toxicity in mice. Clin Toxicol (Phila) 2014; 52(3): 176-80

72. Elliott S, Evans J. A 3-year review of new psychoactive substances in casework. Forensic Sci Int 2014 Oct; 243: 55-60

73. Archer JR, Dargan PI, Lee HM, et al. Trend analysis of anonymised pooled urine from portable street urinals in central London identifies variation in the use of novel psychoactive substances. Clin Toxicol (Phila) 2014; 52(3): $160-5$

74. Giné CV, Espinosa IF, Vilamala MV. New psychoactive substances as adulterants of controlled drugs. A worrying phenomenon? Drug Test Anal 2014; 6(7-8): 819-24

75. Matsuda LA, Lolait SJ, Brownstein MJ, et al. Structure of a cannabinoid receptor and functional expression of the cloned cDNA. Nature 1990; 346: 561-4

76. Herkenham M, Lynn AB, Little MD, et al. Cannabinoid receptor localization in brain. Proc Natl Acad Sci 1990; 87: 1932-6

77. Ishac EJ, Jiang L, Lake KD, et al. Inhibition of exocytotic noradrenaline release by presynaptic cannabinoid CB1 receptors on peripheral sympathetic nerves. Br J Pharmacol 1996; 118: 2023-8

78. Bouaboula M, Rinaldi M, Carayon $\mathrm{P}$, et al. Cannabinoid receptor expression in human leukocytes. Eur J Biochem 1993; 214: 173-80

79. Mouslech Z, Valla V. Endocannabinoid system: an overview of its potential in current medical practice. Neuro Endocrinol Lett 2009; 30: 153-79

80. ANSM. Commission nationale des stupéfiants et psychotropes. 19 février 2009

http://ansm.sante.fr/var/ansm_site/storage/original/ application/cd1d2f893a221733e629d0109256798a.pdf Accessed October 21st , 2014 (16 pages)
81. Arrêté du 24 février 2009 modifiant l'arrêté du 22 février 1990 fixant la liste des substances classées comme stupéfiants. JORF n 0049 du 27 février 2009 page 3494 texte $n^{\circ} 48$.

http: //www . legifrance.gouv. fr/affichTexte.

do?cidTexte $=$ JORFTEXT000020315197\&fastPos $=1 \&$

fastReqId=934782763\&categorieLien=id\&oldAction=rechTexte Accessed October 21st , 2014

82. Seely KA, Patton AL, Moran CL, et al. Forensic investigation of K2, Spice, and "bath salt" commercial preparations: a three-year study of new designer drug products containing synthetic cannabinoid, stimulant, and hallucinogenic compounds. Forensic Sci Int 2013; 233(1-3): 416-22

83. Brents LK, Prather PL. The K2/Spice Phenomenon: emergence, identification, legislation and metabolic characterization of synthetic cannabinoids in herbal incense products. Drug Met Rev 2014; 46(1): 72-85

84. Hermanns-Clausen M, Kneisel S, Szabo B, et al. Acute toxicity due to the confirmed consumption of synthetic cannabinoids: clinical and laboratory findings. Addiction 2013, 108(3): 534-44

85. Brewer TL, Collins M. A review of clinical manifestation in adolescent and young adults after use of synthetic cannabinoids. J Spec Pediatr Nurs 2014; 19: $119-26$

86. Wiebelhaus JM, Poklis JL, Poklis A, et al. Inhalation exposure to smoke from synthetic "marijuana" produces potent cannabimimetic effects in mice. Drug Alcohol Depend 2012; 126(3): 316-23

87. Winstock AR, Barratt MJ. Synthetic cannabis: a comparison of patterns of use and effect profile with natural cannabis in a large global sample. Drug Alcohol Depend 2013; 131(1-2): 106-11

88. Ibrahim S, Al-Saffar F, Wannenburg T. A unique case of cardiac arrest following K2 abuse. Case Rep Cardiol 2014; 2014: 120607

89. Mir A, Obafemi A, Young A. Myocardial infarction associated with use of the synthetic cannabinoid K2. Pediatrics 2011; 128(6): e1622-7

90. Zimmermann US, Winkelmann PR, Pilhatsch M, et al. Withdrawal phenomena and dependence syndrome after the consumption of "spice gold". Dtsch Arztebl Int 2009; 106(27): 464-71

91. Nacca N, Vatti D, Sullivan R, et al. The synthetic cannabinoid withdrawal syndrome. J Addict Med 2013; 7(4): 296-8

92. Kalant H. Adverse effects of cannabis on health: an update of the literature since 1996. Prog Neuropsychopharmacol Biol Psychiatry 2004; 28: 84963

93. Daccarett M, Freih M, Machado C. Acute cannabis intoxication mimickink brugada-like ST segment abnormalities. Int J Cardiol 2007; 119: 235-6

94. Wells DL, Ott CA. The "new” marijuana. Ann Pharmacother 2011; 45(3): 414-7

95. Fisar Z. Inhibition of monoamine oxidase activity by cannabinoids. Naunyn Schmiedebergs Arch Pharmacol 2010; 381: 563-72

96. Stogner JM, Miller BL. Investigating the "bath salt" panic: The rarity of synthetic cathinone use among students in the United States. Drug Alcohol Rev 2013; 32(5): 545-9

Correspondence and offprints: Danièle Debruyne, Centre d'Addictovigilance Service de Pharmacologie, CHU Côte de Nacre, 14033 Caen cedex 09, France E-mail: debruyne-d@chu-caen.fr 